\title{
Rhabdomyolysis and acute renal failure after intense physical activity
}

\author{
Sara Nikpour ${ }^{1}$, Nasim Zamani ${ }^{1}$, Farshid Fahim ${ }^{2}$ and Mohammad Reza Farnia ${ }^{3 *}$ \\ ${ }^{1}$ Emergency department, Loghman Hospital, Shahid Beheshti University of Medical Sciences, Iran \\ ${ }^{2}$ Emergency department, Amir Hospital, Azad University of Medical Sciences, Iran \\ ${ }^{3}$ Emergency department, Imam Reza Hospital, Kermanshah University of Medical Sciences, Iran
}

\section{Introduction}

Acute nontraumatic exertional rhabdomyolysis may arise in individuals with normal muscles when the energy supply to muscles insufficiently meets demands [1]. This case report describes an instance of exercise-induced rhabdomyolysis caused by an extreme physical activity. The patient managed to make full recovery after a period of outpatient treatment.

\section{Case report}

A 23-year-old male was admitted to the emergency department with complaint of worsening lower limbs pain since a few hours ago. No history of recent trauma was noted. He was healthy overall, and his past medical history was unremarkable. On examination the patient was agitated because of pain and mildly dehydrated. His blood pressure was $115 / 65 \mathrm{~mm} \mathrm{Hg}$, pulse rate $106 / \mathrm{min}$, respiratory rate $24 / \mathrm{min}$, and temperature $37.1^{\circ} \mathrm{C}$. Evaluation of lower limbs revealed only mild tender and tense calves. No difference between temperature and size of legs was detected. Sensory and motor exam of four limbs was normal.

Blood investigations showed a total leukocyte count of $18000 / \mathrm{mm}^{3}$ (90.0\% neutrophils), a hemoglobin level of $16.9 \mathrm{~g} / \mathrm{dL}$, and a platelets number of $410000 / \mu \mathrm{L}$. Other lab tests included blood urea nitrogen $44.5 \mathrm{mg} / \mathrm{dl}$, serum creatinine $2.8 \mathrm{mg} / \mathrm{dl}$, serum sodium $140 \mathrm{mmol} / \mathrm{L}$ and potassium $3.7 \mathrm{mmol} / \mathrm{L}$. Serum creatine phosphokinase (CPK) was $58000 \mathrm{U} / \mathrm{L}$, Liver profile and coagulation studies were within normal limits. The urine was mildly dark and the urine blood was +1 without RBC. Limb x-ray investigation was unremarkable. Color doppler sonography showed normal arterial and venous flow. The patient then revealed several hours work in a warm and humid place.

The patient admitted to the emergency ward with diagnosis of rhabdomyolysis and crystalloid and analgesic were administered. Urinary output was recorded. Serial cpk was checked. The limb pain was diminished, however after primary treatment for 6 hours, oliguria occurred, as he had only $20 \mathrm{cc}$ urine. Hence, a vascular catheter inserted and hemodialysis performed. After 3 times daily hemodialysis, serum creatinine lowered and urine flow set in. Finally, the patient discharged

Copyright: (C2019 Nikpour S. This is an open-access article distributed under the terms of the Creative Commons Attribution License, which permits unrestricted use, distribution, and reproduction in any medium, provided the original author and source are credited. home with normal BUN and creatinine values and no sequel after 5 days.

\section{Discussion}

The term rhabdomyolysis refers to disintegration of striated muscle, which results in the release of muscular cell constituents into the extracellular fluid and the circulation. Rapid diagnosis and proper management are essential to prevent complication.

Clinically, creatine kinase is assayed in blood tests as a marker of damage of CK-rich tissue such as in myocardial infarction (heart attack), rhabdomyolysis (severe muscle breakdown), muscular dystrophy, autoimmune myositides, and acute kidney injury.

Rhabdomyolysis is a condition in which skeletal muscle cells break down, releasing intracellular proteins, including creatine kinase and myoglobin, intravascularly. Clinical symptoms may include the classical triad of muscle pain, weakness, and brown urine, but all of these symptoms may not see in every patients.

\section{Conclusion}

In this case, we report a young patient who had only severe muscular pain without significant weakness and dark urine. The emergency physicians should be vigilant about that, so that late diagnosis and treatment can lead to acute renal failure and its complication.

\section{References}

1. Keltz E, Khan FY, Mann G (2013) Rhabdomyolysis. The role of diagnostic and prognostic factors. Muscles Ligaments Tendons J 3: 303-312.

2. Sinert R, Kohl L, Rainone T, Scalea T (1994) Exercise induced rhabdomyolysis. Ann Emerg Med 23: 1301-1306.

3. Teitjen DP, Guzzi LM (1989) Exertional rhabdomyolysis and acute renal failure following the Army Physical Fitness Test. Mil Med 154: 23-25.

4. Cervellin G, Comelli I, Lippi G (2010) Rhabdomyolysis: historical background, clinical, diagnostic and therapeutic features. Clin Chem Lab Med 48: 749-756.

5. Bosch X, Poch E, Grau JM (2009) Rhabdomyolysis and acute kidney injury. $N$ Engl $J$ Med 361: 62-72.
${ }^{\star}$ Correspondence to: Mohammad Reza Farnia, Emergency department, Imam Reza Hospital, Kermanshah University of Medical Sciences, Iran, E-mail: Mr.farnia@kums.ac.ir

Received: October 15, 2019; Accepted: December 03, 2019; Published: December 06, 2019 